\title{
Effect of weight loss with or without orlistat treatment on adipocytokines, inflammation, and oxidative markers in obese women
}

\author{
Maria Bougoulia, Athanassios Triantos, George Koliakos
}

Biochemistry Department, Aristoteles University Medical School, Thessaloniki, Greece

\begin{abstract}
OBJECTIVE: The aim of this study was to evaluate the levels of adipose tissue related hormones, cytokines, and antioxidative substances in obese women before and after intervention with diet alone or with diet plus an inhibitor of gastrointestinental lipase-orlistat. DESIGN: Seventy-one obese women of childbearing age were included in the study and were randomly assigned into two groups according to the type of intervention: group $\mathrm{A1}(\mathrm{n}=35)$ included women who received orlistat as well as a hypocaloric diet, and group $\mathrm{A} 2(\mathrm{n}=36)$ included women who were only on hypocaloric diet. The intervention period lasted 6 months. Anthropometric parameters, such as Body Weight (BW), Body Mass Index (BMI), Waist Circumference (WC), and \%Body fat (BF) were recorded. Insulin, leptin, resistin, interleukin-6 (IL-6), insulin like growth factor 1 (IGF-1), tumor necrosis factor $\alpha$ (TNF $\alpha$ ), adiponectin, hsC-reactive protein (CRP), glutathione peroxidase, and isoprostane were determined by appropriate methodology prior to and following the 6-month intervention period. Insulin resistance was measured using the homeostasis model assessment index (HOMA-IR). All participants had normal glucose tolerance. RESULTS: In both groups BMI values were lower after intervention and all measured parameters were ameliorated. A statistically significant difference was found between group A1 (orlistat plus diet) and group A2 (diet only) with regard to the levels of triglycerides, CRP, TNF- $\alpha$, IGF-1, and isoprostane, even after correcting for weight loss. CONCLUSION: Hypocaloric diet plus orlistat in obese women is superior to diet alone with regard to the changes observed in adipokines, CRP, TNF $\alpha$, triglycerides, IGF-1, and oxidative stress following intervention.
\end{abstract}

Key words: Body mass index, Orlistat, Obesity, Tumor necrosis factor- $\alpha$, Adiponectin, C-reactive protein, Glutathione peroxidase, Isoprostane

\section{INTRODUCTION}

Obesity is fast evolving into an epidemic, its

Address correspondence and requests for reprints to: Dr M Bougoulia, 4 Imeras Str., Kalamaria, 55132, Thessaloniki, E-mail: mariabougoulia@hotmail.com Received 11-04-06, Revised 18-08-06, Accepted 25-08-06 prevalence in the developed countries of the western world having increased markedly over the past few decades. ${ }^{1}$ Obesity is associated with increased cardiovascular morbidity and mortality ${ }^{2,3}$ and is now considered a major independent risk factor. ${ }^{4}$ Obesity affects all age groups and has major sequelae such as 
diabetes mellitus type 2 (DM2), cardiovascular disease, hypertension, hyperlipidaemia, and the metabolic syndrome..$^{5-7}$ It has become evident that adipose tissue synthesizes and secretes many biologically active products that exert effects either within the adipose tissue itself or in distant tissues. The metabolic perturbations of obesity can promote the process of atherosclerosis and affect endothelial function as well as the mechanisms of oxidative stress. Vascular endothelial dysfunction (VED) plays a pivotal role in the pathogenesis of atherosclerosis ${ }^{8}$ and enhances the risk of future cardiovascular events. ${ }^{9} 10$ The presence of VED has been demonstrated in overweight patients with insulin resistance ${ }^{11}$ and with visceral obesity. ${ }^{12,13}$ Therefore, VED may be an important link between obesity per se and heightened cardiovascular risk. Adipocytes are able to synthesize and secrete several cytokines, such as leptin, ${ }^{14}$ tumor necrosis factor $\alpha$ (TNF- $\alpha),{ }^{15}$ interleukin 6 (IL-6), ${ }^{16-}$ ${ }^{18}$ and the more recently identified adipocytokines, adiponectin, ${ }^{19-21}$ and resistin. ${ }^{22-24}$ Indeed, the expression or production of the above-mentioned cytokines was shown to be directly related to the degree of obesity $^{15-17,25}$ and therefore highly likely to be involved in obesity-related insulin resistance. ${ }^{26}$ Leptin, the product of the $o b$ gene,${ }^{14}$ is primarily produced by the adipocyte and is strongly positively correlated with body weight and adiposity in man. Both leptin and its receptor share structural and functional similarities with the IL-6 family of cytokines, and leptin appears to play a critical role in the inflammatory response. ${ }^{27}$ Leptin in the physiological range may serve as a physiological regulator of cardiovascular function, whereas elevated plasma leptin levels due to tissue leptin resistance ${ }^{28,29}$ may act as a pathophysiological trigger and/or marker for cardiovascular diseases. Human adiponectin consists of 244 amino acids and appears to be linked to glucose homeostasis since plasma adiponectin levels are lower in diabetic subjects ${ }^{19,30}$ and are positively correlated with glucose utilization. Adiponectin levels are lower in obese (defined by BMI) than in non-obese subjects. ${ }^{31} \mathrm{Re}$ sistin, also called adipocyte-secreted factor (ADSF), is a novel hormone secreted by adipocytes and has been considered a link between obesity and insulin resistance or diabetes. ${ }^{22,32,33}$ Resistin belongs to a family of cysteine-rich secreted proteins expressed in adipose tissue, heart, lung, and tongue. ${ }^{33,34}$ Initial studies in mice suggested that resistin mediates insulin resistance by antagonizing insulin action and modulating one or more steps in the insulin-signaling pathway. $22,35,36$ The synthesis of C-reactive protein (CRP) by the liver is largely regulated by IL- $6 .{ }^{37}$ IL-6 is a cytokine produced by different cell types, including immune cells, adipocytes, and endothelial cells. ${ }^{37}$ IL-6 mediates inflammatory responses and constitutes a significant proatherogenic factor.

A growing body of evidence has suggested the role of low grade inflammation as a link between obesity, insulin resistance (IR), and endothelial dysfunction. Increased serum levels of inflammatory biomarkers, such as CRP have been reported in obese subjects and have been related to the degree of insulin resistance and endothelial dysfunction. Several mechanisms have been suggested to elucidate the obesityrelated low-grade inflammation. Firstly, fat tissue is an important source of proinflammatory, i.e. TNF- $\alpha$ and IL-6, and antiinflammatory, i.e. adiponectin substanes. Secondly, IR can increase inflammation by interfering with the antiinflammatory effect of insulin. . $^{17,24}$

A number of epidemiological studies have demonstrated an association of CRP levels with increased risk of myocardial infarction (MI), stroke, sudden cardiovascular death, and peripheral vascular disease. ${ }^{38}$ Furthermore, data from population studies have demonstrated that hsCRP measurement identifies a higher risk for cardiovascular events in individuals with the metabolic syndrome, adding prognostic information at every level of severity of the syndrome. ${ }^{38,39}$ Most importantly, hsCRP adds important prognostic information at all levels of LDL cholesterol and at all levels of risk, as determined by the Framingham Risk Score. ${ }^{39}$ Largely on the basis of these data, the American Heart Association and the Center for Disease Control and Prevention recently issued the first guidelines for the use of hsCRP in clinical practice. ${ }^{40}$

IGF-1 is a major endocrine and paracrine regulator of tissue growth and metabolism with at least six binding proteins controlling its bioavailability. Smith et $\mathrm{al}^{41}$ suggest that adipose tissue is a larger source of IGF-1 than the liver.

Obesity is characterized by oxidative stress. Oxi- 
dative stress is a term used to define the imbalance in the rate at which the intracellular content of free radicals, produced through a number of cellular events, increases relative to the capacity of the cell to dispose these oxidants. When not neutralized, these free radicals have the capacity to alter the integrity of numerous molecules such as proteins and DNA. F2isoprostanes are the most reliable indicators of oxidant stress; their role in pathophysiologic processes is unknown. ${ }^{42}$ The measurement of $F_{2}$ isoprostanes may represent an important development in the assessment of free radical generation and oxidant stress in vivo. Glutathione in the reduced state (GSH) is an indirect indicator of oxidative stress. It may also be an important antiatherogenic agent, is present in human plasma and intracellularly, and inhibits free radical formation. ${ }^{43}$

There is significant data accumulation concerning the endocrine function of adipose tissue in normal individuals. The relationship between cytokines, proinflammatory products, and oxidative stress, as well as their involvement in the pathogenesis of cardiovascular diseases still require further elucidation.

Pharmacological agents are often used in the treatment of obesity. Orlistat inhibits the gastrointestinal lipase and consequently reduces the absorption of dietary fat. ${ }^{44}$ Orlistat has been shown to reduce weight in obese subjects and decrease the risk of cardiovascular disease. Orlistat-induced weight reduction has recently been associated with a decrease in serum levels of both IL-6 and hs-CRP in obese subjects. ${ }^{45-47}$

Based on the data briefly outlined, we considered it interesting to study the levels of adipocytokines, oxidative stress, and inflammation markers in healthy obese women and to determine the differential effect of hypocaloric diet alone and of the combination of hypocaloric diet and orlistat in the above parameters following a 6-month intervention period. The results are herein reported.

\section{SUBJECTS AND METHODS}

A total of 71 obese women, aged $36.7 \pm 8.3 \mathrm{yr}$ $($ mean \pm SD) were included in the study. All participants were informed about the objectives of the study and volunteered to participate. All individuals included in the study had at least two menses in the 3 months before testing, registered normal blood pressure, and displayed a normal response to oral glucose tolerance test (OGTT).

Additional exclusion criteria included hormone replacement therapy, pregnancy, lactation, psychiatric or neurological disorders, alcohol abuse, a history or the presence of malignancy, coronary heart disease, and cerebrovascular disease. Continuing use of antihypertensive medication was permitted provided that the dose had been stable for at least 3 months before entry into the study.

None of the subjects were taking any medication known to influence lipid metabolism. Apart from obesity, all obese subjects were in good health and had had stable body weight for at least 12 months prior to entering the study. None was engaged in any type of exercise program or was excessively sedentary. All participants underwent physical examination, measurement of fat mass, and complete biochemical investigations (glucose, total cholesterol, triglycerides, HDL, LDL, SGOT, SGPT, urea, creatinine, uric acid).

Biochemical and hormonal investigations were carried out both at baseline and after the treatment period following an overnight fast. Biochemical and hormonal measurements were performed on frozen plasma samples obtained by centrifugation of freshly drawn blood (3000 Xg for $20 \mathrm{~min}$ at $4 \mathrm{C}$ ) and subsequent storage at $-70 \mathrm{C}$. These investigations included measurement of insulin, leptin, resistin, interleukin-6 (IL-6), insulin-like growth factor-1 (IGF-1), tumor necrosis factor- $\alpha$ (TNF- $\alpha$ ), adiponectin, high sensitive $\mathrm{C}$-reactive protein (hsCRP), glutathione peroxidase, and isoprostane. Anthropometric parameters such as Body Weight (BW), Height, Body Mass Index (BMI), Waist Circumference (WC) and Waist to Hip ratio $(\mathrm{W} / \mathrm{H})$, and $\%$ Body fat as well $\%$ fat free mass (FFM) were also evaluated. Anthropometric indices of women in A1 and A2 are presented in Table 1. Weight in Kg was determined using a standard beambalance scale and with the subjects barefoot and wearing light indoor clothing. Height in centimeters was measured using a meter rule built into the scale. BMI was calculated by dividing weight in $\mathrm{Kg}$ 
Table 1. Anthropometric characteristics of groups A1 and A2

\begin{tabular}{lccc}
\hline & $\begin{array}{c}\text { Group A1 } \\
\text { N=35 }\end{array}$ & $\begin{array}{c}\text { Group A2 } \\
\mathbf{N = 3 6}\end{array}$ & $\begin{array}{c}\mathbf{p} \\
\text { value }\end{array}$ \\
\hline Age (yr) & $38 \pm 7.1$ & $35.4 \pm 9.2$ & 0.931 \\
Weight $(\mathrm{kg})$ & $98.6 \pm 14.9$ & $102.1 \pm 18.7$ & 0.377 \\
Body mass index $\left(\mathrm{Kg} / \mathrm{m}^{2}\right)$ & $37.2 \pm 5.3$ & $38.5 \pm 7$ & 0.742 \\
Waist to hip ratio & $0.9 \pm 0.05$ & $0.9 \pm 0.05$ & 0.610 \\
Waist circumference (cm) & $109.3 \pm 12.7$ & $108.5 \pm 10.6$ & 0.733 \\
\%body fat & $43.3 \pm 5.4$ & $42.5 \pm 8.1$ & 0.368 \\
\%fat free mass & $56.7 \pm 5.8$ & $57.9 \pm 8.2$ & 0.352 \\
\hline
\end{tabular}

by height in meters squared. Obesity was defined as a BMI greater than $30 \mathrm{~kg} / \mathrm{m}^{2}$. Waist circumference was measured with a flexible measuring tape, taking as a reference the midway line between the costal inferior border and the iliac crest. Body fat mass was evaluated by a bioelectric impedance analysis device (Bodystat Ltd, Isle of Man, Bodystat 1500).

Bio-electrical impedence analysis (BIA) measures the impedance or opposition to the flow of an electric current through the body fluids contained mainly in the lean and fat tissue. Impedance is thus proportional to body water volume (TBW). In practice, a small constant current, typically $400 \mathrm{uA}$ at a fixed frequency, usually $50 \mathrm{kHz}$, is passed between electrodes spanning the body and the voltage drop between electrodes provides a measure of impedance. Prediction equations, previously generated by correlating impedance measures against an independent estimate of TBW, may be used subsequently to convert measured impedance to a corresponding estimate of TBW. Lean body mass is then calculated from this estimate using an assumed hydration fraction for lean tissue. Fat mass is calculated as the difference between body weight and lean body mass. ${ }^{48,49}$ All women included in the study also displayed a normal response to oral glucose tolerance test (OGTT). OGTT was performed as follows: all subjects ingested a $75 \mathrm{~g}$ glucose solution after an overnight fast. Serum samples were collected before and $30,60,90$, and $120 \mathrm{~min}$ after the glucose load. The criteria developed by the World Health Organization Expert Committee on Diabetes Mellitus were used to determine whether subjects had normal glucose tolerance. (2-h glucose concentration $<140 \mathrm{mg} / \mathrm{dl})^{50}$ or not. Insulin resistance was calculated based on the homeostasis model assessment index (HOMAIR) HOMA-IR has been suggested as a method to assess insulin resistance from the fasting glucose and insulin concentrations (HOMA-IR = fasting insulin (units/ml)x fasting glucose $(\mathrm{mmol} / \mathrm{l}) / 22,5) .{ }^{51}$

The obese women were randomly subdivided into two groups according to the type of treatment: group A1 $(n=35)$ included women who received orlistat, an inhibitor of the gastrointestinal lipase, as well as a hypocaloric diet, and group A2 $(n=36)$ included women who were only on a hypocaloric diet. The duration of intervention was 6 months. The diet was calculated using the formula: [18-40 $\mathrm{y}=0,0621 \mathrm{x}$ weight in $\mathrm{Kg}+2,0357=---\mathrm{mJ} /$ day x $240=----K c a l /$ day, adjusting with daily activities: ----Kcal/day x---coefficient of daily activities =-----Kcal/day, in order to have a hypo- caloric diet ----Kcal/day-600Kcal/day]. ${ }^{52}$ The energy distribution of this diet was composed of $50 \% \mathrm{CHO}, 30 \%$ fat, and $20 \%$ protein.

Serum glucose levels were measured using a chromatographic method (bioanalyzer wako chemicals $\mathrm{GmbH}$ ), cholesterol, triglyceride, and HDL were measured by standardized laboratory methods and LDL-cholesterol level was calculated with the Friedewald formula. hs-CRP was measured automatically by a nephelometric latex immunoassay (Roche-Diagnostics). The sensitivity of hs-CRP was $0.11 \mathrm{mg} /$ liter. The intraassay CVs of hs-CRP was 1.34 , and the interassay CVs of hs-CRP was 5.70 at the respective cut-offs of the reference range. Insulin was determined by immunoradiometric assay using a Sorin-Biomedica Kit (Saluggia, Italy). The lower limit of detection for insulin was $0.3 \mu \mathrm{IU} / \mathrm{ml}$ while inter-assay and intra -assay coefficients of variation (CV) were 6.9 and $6.4 \%$, respectively. Normal range for our laboratory is $2-25 \mu \mathrm{IU} / \mathrm{ml}$. Leptin was measured by radioimmunoassay using a mediagnost Kit (Tuebingen-Germany) which utilizes a high affinity polyclonal andibody specific for this protein The lower limit of detection for leptin was $0.04 \mathrm{ng} / \mathrm{ml}$ while inter-assay and intra-assay coefficients of variation were $7.6 \%$ and $5 \%$, respectively.

Plasma levels of glutathione peroxidase were determined by the use of an enzymatic assay (BIOXYTECH of the company OxisResearch, Inc Portland, 
USA) that allows a recovery of GSH $>90 \%$ and has no appreciable interference with other thiols present in the plasma or in the reactive mixture. Levels of isoprostane (8-iso-PGF2) were determined using the enzymatic method ELISA by Assay Designs' Correlate-EIA $^{\mathrm{TM}}$ Direct 8-iso-Prostaglandin F2kit. Serum levels of TNF- $\alpha$ and IL- 6 were determined by enzyme-linked immunosorbent assay (Quantikine High Sensitivity TNF- $\alpha$ and Quantikine IL-6; $\mathrm{R} \& \mathrm{D}$ Systems, Oxford, UK). The sensitivity of these assays was $0.18 \mathrm{pg} / \mathrm{mL}$, and $0.70 \mathrm{pg} / \mathrm{mL}$ for TNF- $\alpha$ and IL-6, respectively. Adiponectin and resistin were determined using the enzymatic method ELISA by ACRP30 ELISA kit (Linco Research and Phoenix Pharmaceuticals, Inc-USA). IGF-I concentration was measured by an IGF-I ELISA kit (DSL-10-5600; Diagnostic Systems Laboratories, Inc., Webster, TX).

\section{STATISTICAL METHODS}

Results are expressed as mean \pm standard deviation. The unpaired t-test was used for comparison of the variables between groups A1 and A 2 at baseline. We used the paired t-test for comparison of the variables between baseline and 6 months post intervention in both groups. Correlations were determined by the Pearson correlation coefficient method. For covariance analysis the ANCOVA method was applied. $P$-values $<0.05$ were considered statistically significant.

\section{RESULTS}

The characteristics of both groups (A1 and A2) are presented in Table 1 . There were no significant differences between groups $\mathrm{A} 1$ and $\mathrm{A} 2$ regarding the anthropometric parameters prior to intervention.

The biochemical and hormonal values of the two groups before intervention are presented in Table 2. As previously shown, IGF-1, glutathione peroxidase, and adiponectin were significantly lower in the total group of obese women than in the controls (all p values were less than 0.001).$^{53}$ Between groups A1 and A2 there was no significant difference in biochemical and hormonal levels except for cholesterol value which showed a suggestive difference.
Table 2. Biochemical and hormonal values in groups A1 and A2, before intervention

\begin{tabular}{lccc}
\hline & Group A1 & Group A2 & p-value \\
\hline Chol $(\mathrm{mg} / \mathrm{dl})$ & $187.6 \pm 38.2$ & $209.5 \pm 43.7$ & 0.05 \\
Trigl. $(\mathrm{mg} / \mathrm{dl})$ & $127.7 \pm 46.8$ & $141.5 \pm 42.9$ & 0.498 \\
HDL $(\mathrm{mg} / \mathrm{dl})$ & $40.8 \pm 10.7$ & $42.1 \pm 10.3$ & 0.944 \\
LDL $(\mathrm{mg} / \mathrm{dl})$ & $127.4 \pm 32.8$ & $131.2 \pm 43.9$ & 0.123 \\
hsCRP $(\mathrm{mg} / \mathrm{l})$ & $9.37 \pm 5.5$ & $8.58 \pm 3.9$ & 0.816 \\
Insulin $(\mathrm{IU} / \mathrm{ml})$ & $39.2 \pm 31.5$ & $41 \pm 30$ & 0.845 \\
HOMA-IR & $9.4 \pm 8.2$ & $10.1 \pm 8.2$ & 0.722 \\
Leptin $(\mathrm{ng} / \mathrm{ml})$ & $90.1 \pm 30$ & $88.7 \pm 29.3$ & 0.955 \\
IL-6 $(\mathrm{pg} / \mathrm{ml})$ & $82.3 \pm 17$ & $83 \pm 17$ & 0.770 \\
IGF-I $(\mu \mathrm{g} / \mathrm{L})$ & $102.9 \pm 55.4$ & $97 \pm 42.7$ & 0.076 \\
TNF- $\alpha(\mathrm{pg} / \mathrm{ml})$ & $43.05 \pm 15.9$ & $41.17 \pm 12.7$ & 0.440 \\
Isoprostane $(\mathrm{pg} / \mathrm{ml})$ & $5298.2 \pm 2559.3$ & $5218.5 \pm 2450.7$ & 0.405 \\
Glutathione & $22 \pm 9.8$ & $22.3 \pm 9.5$ & 0.192 \\
Peroxidase $(\mathrm{ng} / \mathrm{ml})$ & & & \\
Resistin $(\mathrm{ng} / \mathrm{ml})$ & $22.3 \pm 8.1$ & $23.7 \pm 9.1$ & 0.538 \\
Adiponectin $(\mathrm{ng} / \mathrm{ml})$ & $17.2 \pm 4.9$ & $20.5 \pm 6.2$ & 0.375 \\
\hline Chol cholesterol; Tri & & & \\
\hline
\end{tabular}

Chol: cholesterol; Trig: triglycerides; HDL: high density lipoprotein; IL-6: interleukin 6; hsCRP: C reactive protein; IGF-1: insulin-like growth factor 1 ; TNF- $\alpha$ : Tumor necrosis factor $\alpha$; HOMA-IR: homeostasis model assessment index.

For SI units multiply for insulin by 7.175 , for cholesterol, LDL and HDL by 0.02586 , for triglycerides by 0.01536 . Normal values (range): resistin; 7-16ng/ml, TNF- $\alpha$; 1.2-7.8pg/ml, adiponectin $28.2-110 \mathrm{ng} / \mathrm{ml}$

The biochemical and hormonal values as well as anthropometric indices of the two groups (A1 and A2) before and after intervention are presented in Table 3. The mean weight, BMI, W/H, waist circumference, \%body fat, cholesterol, triglycerides, CRP, insulin, HOMA-IR, leptin, resistin, interleukin-6, TNF- $\alpha$, and isoprostane were significantly reduced in both groups following intervention, whereas IGF1 , glutathione peroxidase, and adiponectin levels were increased significantly in both groups after intervention.

HDL was significantly lower in group A2 post intervention whereas in group A1, a small non significant rise was observed.

As the data in Table 4A indicate, after interven- 
Table 3. Anthropometric indices, biochemical, and hormonal levels in groups A1 and A2, before and after intervention

\begin{tabular}{|c|c|c|c|c|c|c|}
\hline \multirow[b]{2}{*}{ Parameter } & \multicolumn{3}{|c|}{ Group A1(Diet plus orlistat) } & \multicolumn{3}{|c|}{ Group A2 (Only Diet) } \\
\hline & Before & After & $P$ value & Before & After & $P$ value \\
\hline Weight (Kg) & $98.6 \pm 14.9$ & $75.4 \pm 12.7$ & $<0.001$ & $102.1 \pm 18.7$ & $82.5 \pm 14.8$ & $<0.001$ \\
\hline $\operatorname{BMI}\left(\mathrm{Kg} / \mathrm{m}^{2}\right)$ & $37.2 \pm 5.3$ & $28.42 \pm 4$ & $<0.001$ & $38.5 \pm 7$ & $30.9 \pm 5.7$ & $<0.001$ \\
\hline $\mathrm{W} / \mathrm{H}$ ratio & 0.9 & 0.8 & $<0.001$ & 0.9 & 0,8 & $<0.001$ \\
\hline Waist circumference $(\mathrm{cm})$ & $109.3 \pm 12.7$ & $97.4 \pm 12.7$ & $<0.001$ & $108.5 \pm 10.6$ & $94.1 \pm 9.4$ & 0.028 \\
\hline \%body fat & $43.3 \pm 5.4$ & $31.4 \pm 4.8$ & $<0.001$ & $42.5 \pm 8.1$ & $34.7 \pm 7.3$ & $<0.001$ \\
\hline$\%$ free fat mass & $56.7 \pm 5$ & $66.9 \pm 4.7$ & $<0.001$ & $57.9 \pm 8.2$ & $64.68 \pm 6.9$ & $<0.001$ \\
\hline Chol (mg/dl) & $197.6 \pm 38.2$ & $176.4 \pm 32.2$ & 0.002 & $209.5 \pm 43.7$ & $169.7 \pm 27.2$ & $<0.001$ \\
\hline Trigl. (mg/dl) & $127.7 \pm 46.8$ & $89.9 \pm 23.1$ & $<0.001$ & $141.5 \pm 42.9$ & $125 \pm 40$ & 0.002 \\
\hline HDL (mg/dl) & $40.8 \pm 10.7$ & $44.3 \pm 8.3$ & NS & $42.1 \pm 10.3$ & $33.9 \pm 8.2$ & $<0.001$ \\
\hline $\mathrm{LDL}(\mathrm{mg} / \mathrm{dl})$ & $127.4 \pm 32.8$ & $93.5 \pm 21.8$ & $<0.001$ & $131.2 \pm 43.9$ & $116.9 \pm 28.5$ & 0.034 \\
\hline hsCRP (mg/l) & $9.3 \pm 5.5$ & $4.1 \pm 2.8$ & $<0.001$ & $8.5 \pm 3.9$ & $6.6 \pm 3.3$ & 0.007 \\
\hline Insulin (IU/ml) & $39.2 \pm 31.5$ & $23.8 \pm 18.8$ & $<0.001$ & $41 \pm 30$ & $26.9 \pm 18.3$ & $<0.001$ \\
\hline HOMA-IR & $9.4 \pm 8.2$ & $5.3 \pm 4.1$ & $<0.001$ & $10.1 \pm 8.2$ & $6.5 \pm 4.6$ & $<0.001$ \\
\hline Leptin (ng/ml) & $90.1 \pm 30$ & $51.6 \pm 19.5$ & 0.03 & $88.7 \pm 29.3$ & $60.8 \pm 22.4$ & $<0.001$ \\
\hline IL-6 (pg/ml) & $82.3 \pm 17$ & $10.4 \pm 2$ & $<0.001$ & $83 \pm 17$ & $11.7 \pm 3.1$ & $<0.001$ \\
\hline IGF-I (ng/ml) & $102.9 \pm 55.4$ & $230.3 \pm 53.3$ & $<0.001$ & $97 \pm 42.7$ & $287.6 \pm 83.3$ & $<0.001$ \\
\hline TNF- $\alpha(\mathrm{pg} / \mathrm{ml})$ & $43 \pm 15.9$ & $22.3 \pm 7.5$ & $<0.001$ & $41.1 \pm 12.7$ & $32.5 \pm 10.3$ & $<0.001$ \\
\hline Isoprostane $(\mathrm{pg} / \mathrm{ml})$ & $5298.2 \pm 1778.7$ & $1127.5 \pm 467.1$ & $<0.001$ & $5166.4 \pm 1787.2$ & $1472.2 \pm 506.4$ & $<0.001$ \\
\hline Peroxidase of glutathione $(\mathrm{ng} / \mathrm{ml})$ & $22 \pm 9.8$ & $52.3 \pm 15.2$ & $<0.001$ & $22.3 \pm 9.5$ & $48.9 \pm 14.1$ & $<0.001$ \\
\hline Resistin (ng/ml) & $22.30 \pm 8.1$ & $16.7 \pm 5.9$ & $<0.001$ & $23.7 \pm 9.1$ & $17 \pm 5.4$ & $<0.001$ \\
\hline Adiponectin (ng/ml) & $17.29 \pm 4.9$ & $39.8 \pm 13.4$ & $<0.001$ & $20.5 \pm 6.2$ & $35.3 \pm 21.8$ & $<0.001$ \\
\hline
\end{tabular}

Chol: cholesterol; Trig: triglycerides; HDL: high density lipoprotein; IL-6: interleukin 6; hsCRP: C reactive protein; IGF-1: insulin like growth factor 1; TNF- $\alpha$ : Tumor necrosis factor $\alpha$; HOMA-IR: homeostasis model assessment index; NS: Non significant.

For SI units multiply for insulin by 7.175 , for cholesterol, LDL and HDL by 0.02586 , for triglycerides by 0.01536 . Normal values (range): resistin; 7-16ng/ml, TNF- $\alpha ; 1.2-7.8 \mathrm{pg} / \mathrm{ml}$, adiponectin $28.2-110 \mathrm{ng} / \mathrm{ml}$

tion there was a statistically significant difference in the body weight $(\mathrm{p}=0.048)$, body fat $(\mathrm{p}=0.027)$, triglycerides $(\mathrm{p}<0.001)$, CRP $(\mathrm{p}<0.001)$, TNF$\alpha(\mathrm{p}<0.001)$, IGF-1 $(\mathrm{p}<0.001)$, and isoprostane $(\mathrm{p}=0.006)$ between groups A1 and A2.

After controlling for weight level and using analysis of covariance, orlistat was more effective in reducing triglycerides, $p=0.005$, CRP $(p=0.004)$, TNF- $\alpha$ $(\mathrm{p}<0.0005)$, and isoprostane and in increasing IGF1 than diet alone (Table 4B).

The data presented in Table 5 indicate a positive correlation of BMI in the total group of obese women with waist circumference $(r=0.673, p<0.001)$, \% body fat $(\mathrm{r}=0.786, \mathrm{p}<0.001)$, insulin $(\mathrm{r}=0.413, \mathrm{p}<0.001)$, leptin $(r=0.266, p=0.025)$, HOMA-IR $(r=0.459$, $\mathrm{p}<0.001)$, resistin $(\mathrm{r}=0.238, \mathrm{p}=0.046)$, and a negative correlation of BMI with \%free fat mass $(r=$ $-0.734, \mathrm{p}<0.001)$ prior to intervention.

Resistin levels in the total group of obese women was positively correlated with body weight $(\mathrm{r}=0.284$, $\mathrm{p}=0.017)$, BMI $(\mathrm{r}=0.245, \mathrm{p}=0.039)$, insulin $(\mathrm{r}=0.293$, $\mathrm{p}=0.013)$, HOMA-IR $(\mathrm{r}=0.341$, and $\mathrm{p}=0.004)$, and negatively with TNF- $\alpha(r=-0.238, p=0.046)$ before intervention (Table 6). 
Table 4A. Parameters with statistically significant differences between the groups (A1 \& A2) after intervention.

\begin{tabular}{lc}
\hline Parameter & P value \\
\hline Weight & 0.048 \\
Fat & 0.027 \\
Trigl & $<0.001$ \\
CRP & $<0.001$ \\
TNF- $\alpha$ & $<0.001$ \\
IGF-1 & $<0.001$ \\
Isoprostane & 0.006 \\
\hline
\end{tabular}

Table 4B. Parameters with statistically significant differences between the groups (A1 \& A2) after intervention. Adjustment for weight level using ANCOVA

\begin{tabular}{lc}
\hline \multicolumn{1}{c}{ Comparison } & P value (ANCOVA) \\
Group A1 vs GroupA2 & \\
\hline Trigl & $<0.001$ \\
hsCRP & 0.004 \\
TNF- $\alpha$ & $<0.001$ \\
IGF-1 & 0.001 \\
Isoprostane & 0.004 \\
\hline
\end{tabular}

Table 5. Correlations of BMI in the total group with, waist circumference, \%fat, \%free fat mass, insulin, leptin, HOMA-IR, and resistin prior to intervention

\begin{tabular}{cccccccc}
\hline & WC & \% FAT & \%FFM & INS & LEPT & HOMA-IR & RESISTIN \\
\hline $\mathrm{r}$ & 0.673 & 0.786 & -0.734 & 0.413 & 0.266 & 0.459 & 0.238 \\
$\mathrm{p}$ & $<0.001$ & $<0.001$ & $<0.001$ & $<0.001$ & 0.250 & $<0.001$ & 0.046 \\
\hline
\end{tabular}

WC: waist circumference; FFM fat- free mass; HOMA-IR: homeostasis model assessment index; INS: insulin; LEPT: leptin

\section{DISCUSSION}

Obesity is associated with an increased risk of development of cardiovascular diseases. Individuals with a BMI $>30 \mathrm{Kg} / \mathrm{m}^{2}$ have an approximately 4-fold greater risk of developing cardiovascular disease than those who have BMI $<25 \mathrm{Kg} / \mathrm{m}^{2}$. The metabolic perturbations of obesity can promote the process of atherosclerosis and affect endothelial function as well as the mechanisms of oxidative stress. In a previous study ${ }^{53}$ we showed that weight loss in obese women achieved by a hypocaloric diet resulted in amelioration of \%fat, insulin levels, inflammation indices (IL-6 and CRP), and markers of oxidative stress. In the present study, the levels of inflammation markers, of adipose tissue related hormones and cytokines as well as markers of oxidative stress were evaluated in obese women after intervention, which included

Table 6. Correlations between resistin in the total group of obese women and body weight, BMI, insulin, HOMA-IR, and TNF- $\alpha$, prior to intervention

\begin{tabular}{lccccc}
\hline & BW & BMI & INS & HOMA & TNF- $\boldsymbol{\alpha}$ \\
\hline r-Pearson & 0.284 & 0.245 & 0.293 & 0.341 & -0.238 \\
P value & 0.017 & 0.039 & 0.013 & 0.004 & 0.046 \\
\hline
\end{tabular}

either dietary restrictions only (A2 group) or dietary restrictions plus orlistat (A1 group).

Many studies have shown that CRP is a marker that can predict future cardiovascular events independently of more traditional cardiovascular risk factors, such as plasma lipid levels. ${ }^{54-56}$ Because of this, several investigators have suggested that CRP might prove useful in clinical practice ${ }^{57,58}$ as an important pathogenetic factor in atherosclerotic cardiovascular disease. In addition, CRP predicts the development of coronary events even after Framingham global risk is considered..$^{59}$ One link between subclinical inflammation and CHD may be the metabolic syndrome and insulin resistance. In non-diabetic, Insulin Resistance Atherosclerosis Study (IRAS) subjects, CRP levels were significantly correlated with cardiovascular risk factors. ${ }^{60}$ In addition, the levels of CRP were strongly correlated with various parameters related to the metabolic syndrome (dyslipidemia, upper body adiposity, insulin resistance, and hypertension).${ }^{59}$ Furthermore, hyperinsulinemia is related to the production of free radicals. ${ }^{60-63} \mathrm{CRP}$, and other parameters, such as leptin, resistin, TNF- $\alpha$, and IL-6, were high in obese women prior to intervention as previously reported by our group. ${ }^{53}$ 
In accordance with our previously published data, leptin levels were increased in obese subjects and were positively correlated with body weight, BMI $\%$ body fat and negatively with \% free fat mass. ${ }^{65}$ The levels of resistin were positively correlated with body weight, insulin levels, and HOMA-IR.

Low values of glutathione peroxidase along with increased levels of isoprostane in obese women ${ }^{53}$ are indicative of defective protection mechanisms against oxidative stress and consequently carry increased risk for atherosclerosis. Furthermore, low plasma levels of the anti-inflammatory factor adiponectin in the obese group also contributes to the increased cardiovascular risk of these women.

We previously showed ${ }^{53}$ that TNF- $\alpha$ was positively correlated with hsCRP and isoprostane levels after weight loss, a finding indicating that the improvement of inflammation factors results in a decrease of cellular destruction which offers protection against CVD.

Although adiponectin is secreted only from adipose tissue, its levels are consistently lower in obese than in lean subjects, ${ }^{31}$ as is also shown in our groups prior to intervention. This is in contrast to most other adipocytokines, whose levels are increased in obesity in proportion to an increase in total body fat mass. It is possible that, although adiponectin expression is activated during adipogenesis, a feedback inhibition on its production may occur during the development of obesity. For example, adipocyte expression and secretion of adiponectin has been shown to be reduced by TNF- $\alpha .{ }^{65}$

Therefore, it may be reasonable to assume that increased TNF- $\alpha$ and possibly other adipocytokines that are expressed in increased amounts in the obese state may at least be partially responsible for the decreased adiponectin production in obesity.

IGF-1 levels are lower in obese women, ${ }^{66}$ as is also seen in the values of either group prior to intervention in our study. Subjects with visceral obesity also demonstrate reduced levels of IGF-1, independently of total body fat. ${ }^{67}$ Furthermore, IGF-1 is a known modulator of endothelial function via induction of nitric oxide availability. ${ }^{68}$
After an intervention period of 6 months with either therapeutic modality applied in our obese women, there was a significant improvement in the values of BMI, body weight, $\mathrm{W} / \mathrm{H}$ ratio, $\%$ fat, blood lipids, insulin, inflammatory markers, adiponectin, resistin, and IGF-1 as well as in markers related to oxidative stress.

There is no obvious interpretation for the decrease in HDL in group A2 post intervention, a phenomenon not observed in group A1.

It is of interest to point out that in the group of obese women in whom the intervention also included the administration of orlistat, the body weight, \% fat mass, triglycerides, TNF- $\alpha$, CRP, and isoprostane were significantly lower and IGF1 was higher than in the women in whom only dietary restrictions were applied. No difference in leptin, adiponectin, resistin, insulin or glutathione peroxidase was observed between the two groups following intervention. The more favorable effect of orlistat addition to the therapeutic regimen on the various parameters, as outlined, is not easy to interpret. Is it only a secondary effect of a more pronounced weight reduction or an independent effect of induced fat malabsorption? However, after controlling for weight level and using analysis of covariance, orlistat was more effective in reducing triglycerides, $\mathrm{p}<0.001, \mathrm{CRP}(\mathrm{p}=0.004)$, TNF- $\alpha(\mathrm{p}<0.001)$, and isoprostane $(\mathrm{p}=0.004)$ and in increasing IGF1 $(\mathrm{p}<0.001)$ than diet alone.

Damci et $\mathrm{al}^{69}$ found that the administration of orlistat to diabetics augments post-prandial increases of glucagon like peptide-1(GLP-1), which promotes insulin secretion and action. It is currently unknown if the administration of orlistat over long periods of time will continue to provide this beneficial effect.

In conclusion, the data of the present study indicate that individuals with high BMI have increased levels of markers associated with insulin resistance, vascular inflammation, oxidative stress, and atherosclerosis. Loss of weight can improve all these parameters. This effect is more pronounced when orlistat and dietary restrictions are applied compared to intervention which includes only dietary restrictions. 


\section{REFERENCES}

1. World Health Organization 1997 Obesity: Preventing and Managing the Global Epidemic. Report on a WHO Consultation on Obesity; Geneva

2. Stevens J, Cai J, Pamuk ER, Williamson DF, et al, 1998 The effect of age on the association between body mass index and mortality. N Engl J Med 338: 1-8.

3. National Task Force on the Prevention and Treatment of Obesity, 2000 Overweight, obesity, and health risk. Arch Intern Med 160: 898-904.

4. Eckel RH, Krauss RM, 1998 American Heart Association call to actionobesity as a major risk factor for coronary heart disease. Circulation 97: 2099-2100.

5. Terry RB, Page WF, Haskell WL, 1992 Waist-hip ratio, body mass index and premature cardiovascular disease mortality in US Army veterans during a twenty-three year follow up study. Int J Obes 16: 417-423.

6. Walton C, Lees B, Crook D, et al, 1995 Body fat distribution, rather than overall adiposity, influences serum lipids and lipoproteins in healthy men independently of age. Am J Med 99: 459-464.

7. Pouliot MC, Desprıs JP, Lemieux S, et al, 1994 Waist circumference and abdominal sagittal diameterbest simple anthropometric indexes of abdominal adipose tissue accumulation and related cardiovascular risk in men and women. Am J Cardiol 73: 460-468.

8. Luscher TF, Barton M, 1997 Biology of the endothelium. Clin Cardiol 20: Suppl 2: II-3-II-10.

9. Suwaidi JA, Hamasaki S, Higano ST, et al, 2000 Long-term follow-up of patients with mild coronary artery disease and endothelial dysfunction. Circulation 101: 948-954.

10. Schachinger V, Britten MB, Zeiher AM, 2000 Prognostic impact of coronary vasodilator dysfunction on adverse long-term outcome of coronary heart disease. Circulation 101: 1899-1906.

11. Steinberg HO, Chaker H, Leaming R, et al, 1996 Obesity/ insulin resistance is associated with endothelial dysfunctionimplications for the syndrome of insulin resistance. J Clin Invest 97: 2601-2610.

12. Arcaro G, Zamboni M, Rossi L, et al, 1999 Body fat distribution predicts the degree of endothelial dysfunction in uncomplicated obesity. Int J Obes 23: 936-942.

13. Hashimoto M, Akishita M, Eto M, et al,1998 The impairment of flow-mediated vasodilatation in obese men with visceral fat accumulation. Int J Obes Rel Metab Dis 22: 477-484.

14. Caro JF, Sinha MK, Kolaczybski JW, et al, 1996 Leptin: the tale of an obesity gene. Diabetes 45: 1455-1462.

15. Hotamisligil GS, Shargill NS, Spiegelman BM, 1993 Adipose expression of tumor necrosis factor-a: direct role in obesity-linked insulin resistance. Science 259: 87-91.

16. Mohamed-Ali V, Goodrick S, Rawesh A, et al, 1997 Subcutaneous adipose tissue releases interleukin-6, but not tumor necrosis factor- $\alpha$ in vivo. J Clin Endocrinol
Metab 82: 4196-4200.

17. Papanicolau DA, Wilder RL, Manolagas SC, et al, 1998 The pathophysiologic roles of interleukin- 6 in human disease. Ann Intern Med 128: 127-137.

18. Bastard JP, Jardel C, Delattre J, et al, 1999 Evidence for a link between adipose tissue interleukin- 6 content and serum C-reactive protein concentrations in obese subjects. Circulation 99: 2221-2222.

19. Scherer PE, Williams S, Fogliano M, et al, 1995. A novel serum protein similar to $\mathrm{C} 1 \mathrm{q}$ produced exclusively in adipocytes. J Biol Chem 270: 26746-26749.

20. Diez I, 2003 The role of the novel adipocyte-derived hormone adiponectin in human disease. Eur J Endocrinol 148: 293-300.

21. Chandran M, Phillips S, Ciaraldi Th, et al, 2003 Adiponectin: More Than Just Another Fat Cell Hormone? Diabetes Care 26: 2442-2450.

22. Yang WS, Lee WJ, Funahashi T, et al, 2001 Weight reduction increases plasma levels of an adipose-derived anti-inflammatory protein, adiponectin. J Clin Endocrinol Metab 86: 3815-3819.

23. Steppan CM, Bailey ST, Bhat S, et al, 2001 The hormone resistin links obesity to diabetes. Nature 409: 307-312.

24. Sentinelli F, Romco S, Arca M, et al, 2002 Human resistin gene, obesity and type 2 diabetes: mutation analysis and population study, Diabetes 51: 860-862.

25. Mohamed-Ali V, Pinkney JH, Coppack SW, 1998 Adipose tissue as an endocrine and paracrine organ. Int $\mathrm{J}$ Obes 22: $1145-1158$.

26. Yamamoto Y, Hirose H, Saito I, et al, 2002 Correlation of the adipocyte-derived protein adiponectin with insulin resistance index and serum high-density lipoprotein-cholesterol, independent of body mass index, in the Japanese population. Clin Sci 103: 137-142.

27. Fantuzzi G, Faggioni R, 2000 Leptin in the regulation of immunity, inflammation, and haematopoiesis. J Leukocyte Biol 68: 437-446.

28. Yaspelkis BB, Ansari L, Ramey EL, et al, 1999 Chronic leptin administration increases insulin-stimulated skeletal muscle glucose uptake and transport. Metabolism 48: 671-676.

29. Ren J, 2004 Leptin and hyperleptinemia - from friend to foe for cardiovascular function. J Endocrinol 181: 1-10.

30. Weyer C, Funahashi T, Tanaka S, et al, 2001 Hypoadiponectimia in obesity and type 2 diabetes: close association with insulin resistance and hyperinsulinemia. J Clin Endocrinol Metab 86: 1930-1935.

31. Arita Y, Kihara S, Ouchi N, et al, 1999 Paradoxical decrease of an adipose-specific protein, adiponectin, in obesity. Biochem Biophys Res Commun 257: 79-83.

32. Kim KH, Lee K, Moon YS, et al, 2001 A cysteine-rich adipose tissue-specific secretory factor inhibits adipocyte differentiation. J Biol Chem 276: 11252-11256.

33. Holcomb IN, Kabakoff RC, Chan B, et al, 2000 FIZZ1, a novel cysteine-rich secreted protein associated with 
pulmonary inflammation, defines a new gene family. EMBO J 19: 4046-4055.

34. Steppan CM, Brown EJ, Wright C, et al, 2001 A family of tissue-specific resistin-like molecules. Proc Natl Acad Sci USA 98: 502-506.

35. Steppan CM, Lazar MA, 2002 Resistin and obesity-associated insulin resistance. Trends Endocrinol Metab 13: $18-23$.

36. Ukkola O, 2002 Resistin-a mediator of obesity-associated insulin resistance or an innocent bystander? Eur J Endorinol147: 571-574.

37. Heinrich PC, Castell JV, Andus T, 1990 Interleukin-6 and the acute phase response. Biochem J 265: 621-636.

38. Ridker PM, 2003 Clinical application of C-reactive protein for cardiovascular disease detection and prevention. Circulation 107: 363-369.

39. Ridker PM, Rifai N, Rose L, et al, 2002 Comparison of $\mathrm{C}$-reactive protein and low-density lipoprotein cholesterol levels in the prediction of first cardiovascular events. $\mathrm{N}$ Engl J Med 347: 1557-1565.

40. Pearson TA, Mensah GA, Alexander RW, et al, 2003 Markers of inflammation and cardiovascular disease: Application to clinical and public health practice: A statement for healthcare professionals from the Centers for Disease Control and Prevention and the American Heart Association. Circulation 107: 499-511.

41. Smith SR, 1996 The endocrinology of obesity. Endocrinol Metab Clin North Am 25: 921-942

42. Sampson MJ, Hughes DA, Gopaul N, et al, 2002 Plasma F2 isoprostanes: direct evidence of increased free radical damage during acute hyperglycemia in type 2 diabetes. Diabetes Care 25: 537-541.

43. Hwang C, Sinskey AJ, Lodish HF, 1992 Oxidized redox state of glutathione in the endoplasmic reticulum. Science 257: 1496-1502.

44. Sjostrom L, Rissanen A, Anderson T, et al, 1998 Randomized placebo-controlled trial of orlistat of weight loss and prevention of weight gain in obese patients. Lancet 352: $167-172$

45. Yesilbursa D, Serdar A, Heper Y, et al, 2005 Sarac M, Coskun S, Kazazoglu AR, Cordan J The effect of orlistatinduced weight loss on interleukin-6 and C-reactive protein levels in obese subjects. Acta Cardiol 60: 265-269.

46. Hsieh CJ, Wang PW, Liu RT, et al, 2005 Orlistat for obesity: benefits beyond weight loss.Diabetes Res Clin Pract 67: 78-83.

47. Esposito K, Pontillo A, Di Palo C, et al, 2003 Effect of weight loss and lifestyle changes on vascular inflammatory markers in obese women: a randomized trial. JAMA 289: 1799-1804.

48. Marra M, 2003 The prediction of basal metabolic rate in young adult, severely obese patients using single-frequency bioimpedance analysis. Acta Diabetol 40: Suppl 1: 139-141.

49. Steiner MC, 2002 Bedside methods versus dual energy
X-ray absorptiometry for body composition measurement in COPD. Eur Respir J 19: 626-631.

50. Report of the expert committee on the diagnosis and classification of diabetes mellitus, 1997. Diabetes Care 20: 1183-1197.

51. Haffner SM, Kennedy E, Gonzalez C, et al, 1996 A prospective analysis of the HOMA-IR model: the Mexico City Diabetes Study. Diabetes Care 19: 1138-1141.

52. Bray G 1998 Contemporary diagnosis and management of obesity, Handbooks and Healthcare Company; Pennsylvania

53. Bougoulia M, Triantos Ath, Koliakos G, 2006 Plasma Interleukin-6, glutathione peroxidase and isoprostane in obese women before and after weight loss. Association with cardiovascular risk factors Hormones (Athens) 5: 192-199.

54. Ridker PM, 2000 Novel risk factors and markers for coronary disease. Adv Intern Med 45: 391-418.

55. Tracy RP, 1999 Inflammation markers and coronary heart disease. Curr Opin Lipidol 10: 435-441.

56. Rifai N, Ridker PM, 2001 Proposed cardiovascular risk assessment algorithm using high-sensitivity C-reactive protein and lipid screening. Clin Chem 47: 28-30.

57. Tracy RP, 1998 Inflammation in cardiovascular disease: cart, horse, or both? Circulation 97: 2000-2002.

58. Festa A, D'Agostino RJ, Howard G, et al, 2000 Chronic subclinical inflammation as part of the insulin resistance syndrome: the Insulin Resistance Atherosclerosis Study (IRAS). Circulation 102: 42-47.

59. Wajchenberg BL, 2000 Subcutaneous and visceral adipose tissue: their relation to metabolic syndrome. Endocrine Reviews 21: 697-738.

60. Krieger-Brauer HI, Kather H, 1992 Human fat cells possess a plasma membrane-bound $\mathrm{H} 2 \mathrm{O} 2$-generating system that is activated by insulin via a mechanism bypassing the receptor kinase. J Clin Invest 89: 1006-1013.

61. De Fronzo RA, Ferrannini E, 1991 Insulin resistance: a multifaceted syndrome responsible for NIDDM, obesity, hypertension and atherosclerotic cardiovascular disease. Diabetes Care 14: 173-194.

62. Katsuki A, SumidaY, Urakawa H, et al, 2004 Increased Oxidative Stress Is Associated With Serum Levels of Triglyceride, Insulin Resistance, and Hyperinsulinemia in Japanese Metabolically Obese, Normal-Weight Men Diabetes Care 27: 631-632.

63. Bougoulia M, Tzotzas T, Efthymiou H, et al, 1999 Leptin concentrations during oral glucose tolerance test (OGTT) in obese and normal weight women. Int J Obes Relat Metab Disord 23: 625-628.

64. Tzotzas T, Bougoulia M, Efthymiou H, et al, 1999 Leptin levels after a fat load in obese and normal weight women. Endocrinologia 2: 30-34.

65. Kappes A, Loffler G, 2000 Influences of ionomycin, dibutyryl-cycloAMP and tumor necrosis factor alpha on intracellular amount and secretion of apM1 in dif- 
ferentiating primary human preadipocytes. Hormone Metab Res 32: 548-554.

66. Frystyk J, Vestbo E, Skjaerbaek C, et al, 1995 Free insulin-like growth factors in human obesity. Metabolism 44: Suppl 4: 37-44.

67. Rasmussen MH, Frystyk J, Andersen T, et al, 1994 The impact of obesity, fat distribution and energy restriction on insulin-like growth factor-1 (IGF-1), IGF-binding protein-3, insulin and growth hormone. Metabolism 43:
315-319.

68. Tsukahara H, Gordienko DV, Tonshoff B, et al, 1994 Direct demonstration of insulin-like growth factor-I induced nitric oxide by endothelial cells. Kidney Int 45: 598-604.

69. Damci T, Yalin S, Balci H, et al, 2004 Orlistat augments postprandial increases in glucagon-like peptide 1 in obese type 2 diabetic patients. Diabetes Care 27: 1077-1080. 